\title{
Management of Acute Abdomen: Acute Appendicitis
}

\author{
Neupane BR ${ }^{1}$, Paudel $\mathbf{S R}^{2}$, Shrestha $\mathbf{A}^{1}$, Bijukchhe $\mathrm{SM}^{1}$, Bhattarai $\mathbf{A}^{1}$, Subedi $\mathbf{P}^{3}$ \\ ' Lecturer, Gandaki Medical College Teaching Hospital, Pokharan Nepal \\ ${ }^{2}$ Consultant Surgeon, Fewa City Hospital, Pokhara, Nepal \\ ${ }^{3}$ Medical officer, Gandaki Medical College Teaching Hospital
}

Keywords:

Acute abdomen, Appendicitis, Appendectomy

\section{Corresponding author}

Dr. Bhoj Raj Neupane, Lecturer Gandaki Medical College \& Teaching Hospital, Pokhara, Nepal E-mail: bhojrajneupane10@gmail.com

\begin{abstract}
Background: Traditionally, appendectomy has been the treatment of choice for acute appendicitis but many times diagnosis can be difficult. Clinicians are looking through different ways to come to the correct diagnosis to decrease negative appendectomy. The aim of this study was to determine relation between clinical pattern, laboratory and ultrasonography findings with histopathological report of appendectomy specimen and to evaluate the Alvarado scoring regarding its usefulness in the early diagnosis in our set up.
\end{abstract}

Methods: Prospective cross-sectional study was carried out in Gandaki Medical College Teaching Hospital and Fewa City Hospital from Jan 1, 2016 to Dec 31, 2018 on consecutively admitted patients with clinical diagnosis of acute appendicitis with study variables as demography, Alvarado score, radiological/laboratory investigations, surgical management, histopathology, and clinical outcome.

Results: Among 1021 patients (48.8\% men, 51.2\% women), patients with Alvarado score offive and more $(967,88.8 \%)$ had abdominal USG and some (134) with score of 5-6 (13.12\%) had CT scan. On the basis which 818patients (151 patients with score 5-6 and 667 with score 7 to 10) underwent emergency appendectomy; 705 (86.19\%) by open and $113(13.81 \%)$ by laparoscopic technique. Appendicitis was suggestive per-operatively in $76.2 \%$ of patients with Alvarado score of 5-6 and $97.4 \%$ of patients with the score of 7-10. Histo-pathologically diagnosis was correct in 752 (91.9\%),91.2\% in open appendectomy and $96.5 \%$ in laparoscopic appendectomy cases. Only two patients had infective complication and no mortality.

Conclusion: Alvarado scoring in patients presenting with acute abdominal pain is reliable predicting tool for acute appendicitis.

\section{INTRODUCTION}

Acute appendicitis is the most common surgical disease with a lifetime risk of 7 to $8 \% .{ }^{1}$ Appendectomy is the most commonly performed emergency operation in the world. ${ }^{1,2}$
Mc Burney, in 1889, had suggested early appendectomy for patients with acute appendicitis3. Three years earlier to that Fitz's had published paper advocating appendectomy for complicated (perforated) acute appendicitis. ${ }^{4}$ Since then the general surgical practice has been to remove 
the appendix when there is a question of appendicitis to prevent its common complication (perforation).

There is great variation in the presentation, severity of disease, radiological workup, and surgical management of patients with acute appendicitis. The initial management of patients with suspected appendicitis still needs to be based on the disease history, physical signs, and basic relevant laboratory tests that suggest the inflammatory response. This involves a subjective synthesis of a large amount of complex information, which relies on the surgeon's knowledge and previous experience with similar patients. So the diagnosis of acute appendicitis is often elusive and made in about $80 \%$ of cases. ${ }^{5,6}$ In about $20 \%$ of cases, difficulty in diagnosis lead to a significant rate of negative appendectomy, which is again, loaded with lot of problems. ${ }^{5}$ There are diagnostic modalities currently available e.g. USG, CT scan to improve the diagnosis of appendicitis but they are underused. ${ }^{7,8}$ In many centers their availability is also inconsistent leaving clinician dependent of clinical and some laboratory parameters for the diagnosis.

Many scoring systems are devised to increase diagnostic accuracy in acute appendicitis, so as to decrease the need of potentially harmful and expensive imaging and ultimately to reduce morbidity and mortality associated with appendicitis. ${ }^{9,10}$ Acute appendicitis grading system based on clinical presentation and imaging should be like a yard stick to provide a uniform patient stratification, and contribute in determining the favorable plan of action in treating acute appendectomy according to the grade of severity and ultimately contribute to decreased morbidity.10 Therefore, this study is conducted.

\section{Patients and methods}

This is a cross-sectional observational study performed in the department of surgery in GMCTH and FCH over a period of 36 months (January 1, 2016 - December 31, 2018). All consecutive 1021 patients admitted to surgical departments with a provisional diagnosis of acute appendicitis were included in the study.

Signs, symptoms, and laboratory findings of all the patients with abdominal pain of up to 3 days' duration were analyzed and Alvarado score was calculated for each Table 1).
Inclusion criteria: All patients with suspected clinical diagnosis of acute appendicitis, confirmed by imaging and seen by a surgeon were included in the study.

Table 1: Alvarado score for diagnosis of acute appendicitis

\begin{tabular}{|c|c|c|}
\hline Features & & Value allotted \\
\hline Migratory pain & & 1 \\
\hline Anorexia & & 1 \\
\hline Nausea, Vomiting & & 1 \\
\hline Tender RIF & & 2 \\
\hline Rebound tenderness & & 1 \\
\hline Elevated temp & & 1 \\
\hline Leukocytosis & & 2 \\
\hline Shift of WBC to left & & 1 \\
\hline \multicolumn{3}{|c|}{ Interpretation of Alvarado score } \\
\hline Score & Diagnosis & Plan of action \\
\hline $1-4$ & Not likely & Conservative treatment \\
\hline $5-6$ & Compatible & Further evaluation \\
\hline $7-8$ & Probable & Surgery \\
\hline $9-10$ & Very probable & Surgery \\
\hline
\end{tabular}

Exclusion criteria: Patients with recurrent pain, with other comorbid conditions and with pregnancy and other obviously diagnosable cases were not taken in the study.

The study was approved by the Human Ethical Committee at Institutional Review Board of the college.

Patients Information on the demography, disease history, clinical findings, Alvarado score, comorbidities, results of radiological and laboratory investigations were recorded and analyzed in all the 1021 patients.

Although surgeons with all levels of experience were involved, the majority of patients admitted for suspicion of appendicitis were initially evaluated by surgical medical officers with limited experience. But final evaluation and decision was made by a consultant surgeon and obviously operated by a senior surgeon.

All the patients with score 7 or more were planned for surgical management, score of 5-7 are further evaluated with USG and in few doubtful cases with CT scan of abdomen. Some of them were decided for operation and few with score of 5-6 and all the patients with the score of 1-4 were conservatively managed. Final diagnosis was confirmed by intraoperative findings and histopathological examination of the removed appendix. Findings of surgical management, clinical outcome and histopathology reports 
were recorded.

Univariate analyses were performed using a chi-square test, or a Fisher's exact test, if the expected value of a cell was $<5$. All tests were two-sided, and p-values of 0.05 were considered statistically significant.

\section{Results:}

Among 1021 patients enrolled in the study, there were 498 (48.78\%) men and 523 (51.22\%) women. Patients' age ranged from 3.5 to 83 years in male (mean 22.12 years) and 5 to 84 years in female (mean 25.93 years). Majority of the patients $(69 \%)$ were in the age range between 11 and 30 (Table 2).

Table 2: Patient demographics

\begin{tabular}{|c|c|c|c|c|c|}
\hline \multirow{2}{*}{\multicolumn{2}{|c|}{ Patient characteristics }} & \multicolumn{4}{|c|}{ Enrolled Patients } \\
\hline & & \multirow{2}{*}{\multicolumn{2}{|c|}{$\begin{array}{l}\text { Male } \quad \text { (\%) } \\
498 \quad(48.78)\end{array}$}} & \multirow{2}{*}{$\begin{array}{l}\text { Female (\%) } \\
523 \quad(51.22)\end{array}$} & \multirow{2}{*}{$\begin{array}{ll}\text { Total } & (\%) \\
1021 & (100)\end{array}$} \\
\hline Total patient & & & & & \\
\hline \multirow{3}{*}{ Operated } & Total & 404 & (49.39) & $414 \quad(50.61)$ & $818 \quad(100)$ \\
\hline & Open & 350 & (86.63) & 335 (80.92) & $705(86.2 \%)$ \\
\hline & Laparoscopic & 54 & (13.37) & 79 (19.08) & $113(13.8 \%)$ \\
\hline \multirow{9}{*}{$\begin{array}{l}\text { Age group } \\
\text { (years) }\end{array}$} & $0-10$ & & 52 & 20 & 72 \\
\hline & $11-20$ & & 168 & 149 & 317 \\
\hline & $21-30$ & & 99 & 148 & 247 \\
\hline & $31-40$ & & 35 & 46 & 81 \\
\hline & 41- 50 & & 28 & 20 & 48 \\
\hline & $51-60$ & & 11 & 18 & 29 \\
\hline & $61-70$ & & 6 & 9 & 14 \\
\hline & 71- 80 & & 3 & 2 & 5 \\
\hline & $80+$ & & 2 & 2 & 4 \\
\hline
\end{tabular}

There is great variation in the presentation, severity of disease, radiological workup, and surgical management of patients having acute appendicitis. The frequency of different features was noted as mentioned below in table 3 .

Table 3: Clinical and laboratory findings in operated patients $(n=818)$

\begin{tabular}{lc}
\hline Findings & Number (\%) \\
\hline Central abdomen pain shift to RLQ & $696(85 \%)$ \\
Right lower abdomen pain & $744(91 \%)$ \\
Right lower abdomen tenderness & $564(69 \%)$ \\
Diffuse tenderness & $172(21 \%)$ \\
Vomiting & $425(52 \%)$ \\
Temperature $>38^{\circ} \mathrm{C}$ & $205(25 \%)$ \\
WBC $>10,000 / \mathrm{ml}$ & $671(82 \%)$ \\
\hline
\end{tabular}

Alvarado scoring was done in all 1021 patients (Table 1) and found as: Alvarado score of 1-4 in 147 (14.4\%) patients,
5-6 in 207 (20.3\%) patients and 7 or more in 667 (65.3\%) patients. Out of 1021 patients with acute abdominal pain 917 (89.81\%) patients underwent an abdominal USG and 134 (13.1\%) patients further required abdominal CT scan. Remaining 104 (10.19\%) patients were diagnosed acute appendicitis without help of radiological study and proceeded for surgery (Table 4).

Table 4: Patients management according to the Alvarado Score

\begin{tabular}{|c|c|c|c|c|}
\hline \multirow{2}{*}{ Procedure } & \multicolumn{3}{|c|}{ Alvarado score } & \multirow[t]{2}{*}{ Total $(\%)$} \\
\hline & $\leq 4$ & $5-6$ & $\geq 7$ & \\
\hline Total & 147 (14.4\%) & 207 (20.3\%) & $667(65.3 \%)$ & 1021 \\
\hline Not operated & $147(100 \%)$ & $56(27.0 \%)$ & 0 & $203(80.1 \%)$ \\
\hline Operated & 0 & $151(73.0 \%)$ & $667(100 \%)$ & 818 (19.9\%) \\
\hline USG done & 147 & 207 & 563 & 917 (89.8\%) \\
\hline CT Scan done & 0 & 87 & 47 & $134(13.1 \%)$ \\
\hline $\begin{array}{l}\text { Radio not } \\
\text { suggestive }\end{array}$ & 147 & $56 \quad(27 \%)$ & 0 & \\
\hline $\begin{array}{l}\text { Radiology } \\
\text { suggestive }\end{array}$ & 0 & $151 \quad(73 \%)$ & $563(100 \%)$ & \\
\hline
\end{tabular}

Those patients with Alvarado score of 7 or more were operated. But for the patients with the score of 5-6 radiological findings were considered before planning the operation. Among them 56 (5.5\%) were conservatively treated and 151 (14.8\%) were taken for operation as suggested by the radiological findings. This way total of $818(80.12 \%)$ patients were taken for appendectomy; $705(86.19 \%)$ of them by open and $113(13.81 \%)$ by laparoscopic technique. There were no specific criteria for choosing a particular technique of appendectomy, but usually by patients' choice. So radiologically negative 56 patients from Alvarado score 5-6 and all the 147 patients from score 1-4 making total of 203 (19.88\%) patients were managed conservatively (Table 4). The number of patients and type of procedure according to the age group is as depicted in the table 5 .

Table 5: Number of cases according to type of operation

\begin{tabular}{cllllllll}
\hline & \multicolumn{3}{c}{$\begin{array}{c}\text { Operated patient } \\
\text { Age } \\
\text { groups }\end{array}$} & \multicolumn{3}{c}{ Number } & \multicolumn{3}{c}{$\begin{array}{c}\text { Type of procedure } \\
\text { Open }\end{array}$} & \multicolumn{2}{c}{ Laparoscopic } \\
& Total & Male & Female & Male & Female & Male & Female \\
\hline $0-10$ & 72 & 52 & 20 & 52 & 20 & - & - \\
$11-20$ & 317 & 168 & 149 & 168 & 149 & 25 & 37 \\
$21-30$ & 247 & 99 & 148 & 99 & 148 & 14 & 20 \\
$31-40$ & 81 & 35 & 46 & 35 & 46 & 6 & 9 \\
$41-50$ & 48 & 28 & 20 & 28 & 20 & 8 & 5 \\
\hline
\end{tabular}




\begin{tabular}{llllllll} 
51-60 & 29 & 11 & 18 & 11 & 18 & 1 & 6 \\
$61-70$ & 15 & 6 & 9 & 6 & 9 & - & 2 \\
$71-80$ & 5 & 3 & 2 & 3 & 2 & - & - \\
$80+$ & 4 & 2 & 2 & 2 & 2 & - & - \\
Total & 818 & 404 & 414 & 350 & 54 & 335 & 79 \\
\hline
\end{tabular}

During operation, appendix was observed frankly inflamed in 115 out of 151 cases (76.2\%) in Alvarado score 5-6 group and in 650 out of 667 cases (97.4\%) in Alvarado score of seven of more group with statistically significance difference (Table 6).

Table 6: Per-operative findings of operated cases

\begin{tabular}{lcc}
\hline Per-operative findings & \multicolumn{2}{c}{ Alvarado score } \\
& $\mathbf{5}-\mathbf{6}$ & $\geq \mathbf{7}$ \\
Total number & $151(100 . \%)$ & $667(100 \%)$ \\
Diseased appendix & $115(76.2 \%)$ & $650(97.4 \%)$ \\
Normal looking appendix & $36(23.8 \%)$ & $17(2.5 \%)$ \\
& $\mathrm{p}<0.050$ & $\mathrm{p}<0.001$ \\
\hline
\end{tabular}

A total of $818(80.12 \%)$ patients underwent surgery, of which 705 (86.19\%) underwent open appendectomy and 113 (13.81\%) laparoscopic appendectomy (Table 5). Among open appendectomy cases some of them also had additional procedure as mentioned in table 7. Among laparoscopic appendectomy cases, two cases had to be converted to open technique because of high up position and difficulty in dissection.

Table 7: Per-operative findings of operated cases

\begin{tabular}{|c|c|c|c|c|}
\hline \multirow{2}{*}{\multicolumn{2}{|c|}{ Per-operative findings }} & \multicolumn{2}{|c|}{ Alvarado score } & \multirow{2}{*}{ Total } \\
\hline & & $5-6$ & $\geq 7$ & \\
\hline \multirow{5}{*}{$\begin{array}{l}\text { Diseased } \\
\text { appendix }\end{array}$} & Inflamed & 76 & 435 & 511 \\
\hline & Gangrenous & 28 & 114 & 142 \\
\hline & Perforated & 9 & 76 & 85 \\
\hline & Abscess & 2 & 25 & 27 \\
\hline & Total & $115(76.2 \%)$ & $650(97.4 \%)$ & $765(93.5 \%)$ \\
\hline \multirow{9}{*}{$\begin{array}{c}\text { Normal } \\
\text { looking } \\
\text { appendix }\end{array}$} & Cecal pathology & 2 & 1 & 3 \\
\hline & Ileal pathology & 4 & 2 & 6 \\
\hline & Meckel diverticulitis & 4 & 1 & 5 \\
\hline & Mesenteric lymphadenitis & 12 & 8 & 20 \\
\hline & Ovarian pathology & 6 & 3 & 9 \\
\hline & Tubal pathology & 5 & 2 & 7 \\
\hline & Others & 3 & - & 3 \\
\hline & Total & $36(24 \%)$ & $17(03 \%)$ & $53(6.5 \%)$ \\
\hline & Total operated cases & 151 & 667 & 818 \\
\hline
\end{tabular}

Per-operative diagnosis of appendicitis was suggestive in
$76.2 \%$ of patients with Alvarado score of 5-6 and 97.4\% of patients with score of 7-10. The diagnosis of acute appendicitis was histo-pathologically confirmed in 752 (91.9\%) (RR=1.11, (1.07-1.14) CI 95\%, p<0.001) out of 818 operated patients, $91.2 \%$ among open appendectomy and $96.5 \%$ among laparoscopic appendectomy cases $(\mathrm{p}<0.05)$. Clinical diagnosis of appendicitis had a sensitivity of 0.82 , a specificity of 0.95 , a positive predictive value of 0.53 . Clinical diagnosis of appendicitis was not supported histopathologically in $8.1 \%$ of cases. The negative appendectomy rate was $4.6 \%$ in males and $6.3 \%$ in females $(\mathrm{p}<0.05)$ (Table 8).

Table 8: Relation of Alvarado Score with histopathological report

\begin{tabular}{|c|c|c|c|c|c|c|c|}
\hline \multirow{2}{*}{\multicolumn{2}{|c|}{$\begin{array}{l}\text { Patient } \\
\text { characteristics }\end{array}$}} & \multirow{2}{*}{\multicolumn{2}{|c|}{$\begin{array}{l}\text { Enrolled Number } \\
\qquad(1021)\end{array}$}} & \multicolumn{4}{|c|}{ Histopathology report } \\
\hline & & & & Positive & (\%) & Negative & $(\%)$ \\
\hline \multirow{2}{*}{ Sex } & Male & 498 & $(48.78 \%)$ & 475 & $95.4 \%$ & 23 & $4.6 \%$ \\
\hline & Female & 523 & $(51.22 \%)$ & 490 & $93.7 \%$ & 33 & $6.3 \%$ \\
\hline \multirow{2}{*}{ Operation } & Open & 705 & $(86.2 \%)$ & 643 & $91.2 \%$ & 62 & $8.8 \%$ \\
\hline & Lap & 113 & $(13.8 \%)$ & 109 & $96.5 \%$ & 4 & $3.5 \%$ \\
\hline \multirow{9}{*}{ Age group } & $0-10$ & 72 & & 65 & $90 \%$ & 7 & \\
\hline & $11-20$ & 317 & & 290 & $91 \%$ & 27 & \\
\hline & $21-30$ & 247 & & 228 & $92 \%$ & 19 & \\
\hline & $31-40$ & 81 & & 77 & $95 \%$ & 4 & \\
\hline & $41-50$ & 48 & & 46 & $96 \%$ & 2 & \\
\hline & $51-60$ & 29 & & 29 & $100 \%$ & 0 & \\
\hline & $61-70$ & 15 & & 14 & $93 \%$ & 1 & \\
\hline & $71-80$ & 5 & & 4 & $80 \%$ & 1 & \\
\hline & $80+$ & 4 & & 3 & $75 \%$ & 1 & \\
\hline
\end{tabular}

There is great variation in the presentation, severity of disease, radiological workup, and surgical management of patients having acute appendicitis. The values of the Alvarado score are significantly higher in the patients with acute appendicitis, compared with the patients of the other diseases (Table 7). Major post-operative complications occurred in two $(0.24 \%)$ patients; Pelvic abscess in one laparoscopic appendectomy patient and synergistic gangrene of right lower abdominal wall in one open appendectomy patient. Both of them recovered satisfactorily in due course of time. There was no mortality observed in the study population.

\section{Discussion}

Acute abdomen is any abdominal disease with acute onset of abdominal pain requiring immediate intervention. 
Abdominal pain is often derived from digestive system diseases but may also be caused by hepato-biliary, urological, gynecological and even neurological entities; however, the incidence varies according to age and disease etiology. Therefore, appropriate primary care should be provided based on careful history taking and clinical findings. The site and characteristics of the abdominal pain, accessory symptoms (pain location, migration, sudden onset, increasing severity, accompaniment with GI bleeding, vomiting, diarrhea, or constipation) should be assessed to differentiate cases requiring emergency surgery.

Acute appendicitis is the most common surgical disease with a lifetime risk of $7-8 \%{ }^{1}$ The lifetime risk of appendectomy is $12 \%$ for men and $25 \%$ for women, making it one of the most commonly performed emergency operation in the world. ${ }^{1,2}$

Epigastric pain, secondarily located in the right lower abdomen, along with tenderness is the most specific sign of acute appendicitis. Improving the diagnostic pathway is the cornerstone for decreasing the rate of negative appendectomy and other risks of wrong diagnosis. It is important to detect patients with advanced appendicitis early.

Imaging techniques (USG, CT) and diagnostic laparoscopy have been used with the hope of yielding a rapid and accurate diagnosis but diagnostic imaging performs less well in place where these facilities are considered luxury in spite of high sensitivity and specificity. ${ }^{7,8}$ Echotomography and tomodensitometry are considered less invasive and less costly procedures, that can lead surgeons identify the appendix and confirm the diagnosis of acute appendicitis or reject. But these modality of investigations are not available everywhere. ${ }^{6}$ The other problems with routine use of diagnostic imaging are potentially harmful ionizing radiation (CT), examiner-dependent efficacy (US), and technique-associated morbidity (diagnostic laparoscopy). ${ }^{6}$

In about $20 \%$ of cases, difficulty in diagnosis lead to a significant rate of negative appendectomy, which is again is loaded with lots of problems. ${ }^{5}$ A populationbased analysis 11 opined similarly with the findings of clinical studies ${ }^{12-14}$ that in about $15 \%$ of appendectomies pathologic evidence of appendicitis was not found. Unnecessary appendectomy is said to be more in women of reproductive ages, which in one study was reported to be as high as $26 \%{ }^{5}$
Before the wide spread use of USG and CT scans, the diagnosis of acute appendicitis was mainly based on symptoms, signs, and laboratory data. A practical score for the early diagnosis of acute appendicitis was established by Alvarado in 1986 and was assessed in this study for its accuracy in pre-operative diagnosis. ${ }^{15}$ With the application of the Alvarado scoring system, we can decrease postoperative morbidity and mortality. ${ }^{16}$ High score was found to be a dependable aid both in the preoperative diagnosis of acute appendicitis and in the reduction of negative appendectomy in men and children but the same was not true for women who had a high false positive rate for acute appendicitis. ${ }^{16} \mathrm{This}$ clinical score can correctly classify the majority of patients with suspected appendicitis, leaving the need for diagnostic imaging or diagnostic laparoscopy to the smaller group of patients with an indeterminate scoring result. ${ }^{17}$

Laparoscopic appendectomy is gaining popularity in the last 10-15 years among surgeons worldwide in the treatment of acute appendicitis. Because of its higher operative time, increased intra-abdominal abscess risk, and higher costs compared to open, it is not yet considered the "gold standard" in the management of acute appendicitis. ${ }^{18-23}$

According to literature 2 to $7 \%$ of appendicitis tends to present with complex features such as a phlegmon or periappendicular abscess. ${ }^{23,24}$ They are treated conservatively followed by interval appendectomy, to reduce the risk of recurrenceand risk of missing an underlyingmalignancy. ${ }^{25,26}$ Overall postoperative complication rates ranged between 10-19\% for uncomplicated acute appendicitis and reaching $30 \%$ in cases of complicated acute appendicitis. ${ }^{15}$ The results of the present study confirm the clinical value of imaging techniques and prognostic scores. Appendectomy remains the most effective treatment of acute appendicitis with low mortality rate. ${ }^{26}$

\section{Conclusions}

There is great variation in the presentation, severity of disease, radiological workup, and surgical management of patients having acute appendicitis. ${ }^{27}$ The results of the present study confirm the clinical value of Alvarado scoring in all cases, and imaging techniques (USG, CT scan) in doubtful cases. Conservative management of doubtful cases of acute appendicitis (Alvarado score 1-4 and radiologically not suggested cases of score of 5-6), with close monitoring. In those cases, presenting with complex 
features such as a lump or peri-appendicular abscess, it is better to treat conservatively followed by interval appendectomy.

\section{Conflict of interest}

The authors declare that they have no conflict of interests.

\section{Funding}

No funding source

\section{REFERENCES}

1. Addiss DG, Shaffer N, Fowler BS, Tauxe RV. The epidemiology of appendicitis and appendectomy in the United States. Am J Epidemiol. 1990;132:910-25.

2. BlomqvistP, Ljung $\mathrm{H}$, Nyren O, Ekbom A. Appendectomy in Sweden 1989-1993 assessed by the Inpatient Registry. J Clin Epidemiol. 1998;51:859-65.

3. McBurney C. Experiences with early operative interference in cases of disease of the vermiform appendix. NY Med J. 1889;50:1676-84.

4. Fitz RH: Perforating inflammation of the vermiform appendix. Am J Med Sci. 1886;92:321-46.

5. Flum DR, Koepsell T. The clinical and economic correlates of misdiagnosed appendicitis Nation-wide analysis. Arch Surg. 2002;37(7):799-804.

6. Vons C. Diagnosis of appendicular syndromes: for a rational approach. J Chir (Paris). 2001 Jun;138(3):1435.

7. Horton MD, Counter SF, Florence MG, Hart MJ. A prospective trial of computed tomography and ultrasonography for diagnosing appendicitis in the atypical patient. Am J Surg. 2000;179:379-81.

8. Pinto Leite N, Pereira JM, Cunha R, Pinto P, Sirlin C. CT evaluation of appendicitis and its complications: Imaging techniques and key diagnostic findings. AJR Am J Roentgenol. 2005;185:406-17.

9. Alvarado A. A practical score for the early diagnosis of acute appendicitis. Ann Emerg Med. 1986;15:557-64.

10. Gomes CA, Sartelli M, Di Saverio S, Ansaloni L, Catena F, Coccolini F, et al. Acute appendicitis: Proposal of a new comprehensive grading system based on clinical, imaging and laparoscopic findings. World J Emerg Surg. 2015;10:60.

11. Flum DR, Morris AKoepsell T, Dellinger EP. Has diagnostic accuracy in appendicitis improved with time? JAMA. 2001;286:1748- 53.

12. Korner H, Sondenaa K, Soreide JA, Andersen E, Nysted $\mathrm{A}$, Lende $\mathrm{TH}$ et al. Incidence of acute nonperforated and perforated appendicitis: Age-specific and sexspecific analysis. World J Surg. 1997;21: 313- 7

13. Lee SL, Walsh AJ, Ho HS. Computed tomography and ultrasonography do not improve and may delay the diagnosis and treatment of acute appendicitis. Arch Surg. 2001;136:556- 62

14. Pittman-WallerVA, Myers JG, StewartRM, DentDL, Page CP, Gray GA et al. Appendicitis: why so complicated? Analysis of 5755 consecutive appendectomies. Am Surg. 2000; 66548- 554.

15. Sartelli M, Baiocchi GL, Di Saverio S, Ferrara F, Labricciosa FM, Ansaloni L, et al. Prospective observational study on acute appendicitis Worldwide (POSAW). World J Emerg Surg. 2018;13:19.

16. Bhattacharjee PK, Chowdhury T, Roy D. Prospective evaluation of modified Alvarado score for diagnosis of acute appendicitis. J Indian Med Assoc. 2002 May; 100(5):310-4.

17. Andersson M, Andersson RE. The appendicitis inflammatory response score: a tool for the diagnosis of acute appendicitis that outperforms the Alvarado score. World J Surg. 2008;32:1843-9.

18. Bennet J, Boddy A, Rhodes M. Choice of approach for appendectomy: A meta-analysis of open versus laparoscopic appendectomy. Surg Laparosc Endosc Percutan Tech. 2007;17:245-55.

19. Liu Z, Zhang P, Ma Y, Chen H, Zhou Y, Zhang M, et al. Laparoscopy or not: A meta-analysis of the surgical effects of laparoscopic versus open appendectomy. Surg Laparosc Endosc Percutan Tech. 2010;20:36270. 
20. Sauerland S, Jaschinski T, Neugebauer EA. Laparoscopic versus open surgery for suspected appendicitis. Cochrane Database Syst Rev. 2010;10:CD001546.

21. Wei B, Qi CL, Chen TF, Zheng ZH, Huang JL, Hu BG, et al. Laparoscopic versus open appendectomy for acute appendicitis: a meta-analysis. Surg Endosc. 2011;25:1199-208.

22. Ohtani H, Tamamori Y, Arimoto Y, Nishiguchi Y, Maeda K, Hirakawa K. Meta-analysis of the results of randomized controlled trials that compared laparoscopic and open surgery for acute appendicitis. J Gastrointest Surg. 2012; 16: 1929-39.

23. Bradley EL 3rd, Isaacs J. Appendiceal abscess revisited. Arch Surg. 1978;113: 130-2.

24. Bagi P, Dueholm S. Nonoperative management of the ultrasonically evaluated appendiceal mass. Surgery. 1987; 101:602-5.

25. Corfield L. Interval appendectomy after appendiceal mass or abscess in adults: what is "best practice"? Surg Today. 2007; 37:1-4.

26. Sartelli M, Viale P, Koike K, Pea F, Tumietto F, van Goor H, et al. WSES consensus conference: guidelines for firstline management of intra-abdominal infections. World J Emerg Surg. 2011;6:2.

27. Laurell H, Hansson LE. Gunnarsson U. Manifestations of acute appendicitis: A prospective study on acute abdominal pain. Dig Surg. 2013;30:198-206. 